\title{
Prevalence and Determinants of Substance Use Among a Sample of Iranian Adolescents with Ease of Access to Drugs: An Application of Social Development Model
}

\section{Roya Shahsavari Bami}

Kerman University of Medical Sciences

Hadi Khoshab

Kerman University of Medical Sciences

Mohammad Mehdi Fadakar Davarani

Kerman University of Medical Sciences

Yunes Jahani

Kerman University of Medical Sciences

Nozar Nakhaee

Kerman University of Medical Sciences

Haidar Nadrian

Tabriz University of Medical Sciences

Abedin Iranpour ( $\nabla$ a.iranpour@kmu.ac.ir)

Kerman University of Medical Sciences

Research article

Keywords: Substance use, social development model, students, adolescence, risky behavior

Posted Date: June 29th, 2020

DOI: https://doi.org/10.21203/rs.3.rs-36862/v1

License: (c) (1) This work is licensed under a Creative Commons Attribution 4.0 International License. Read Full License 


\section{Abstract}

Background Explaining the risk and protective factors of substance use (SU) is the most important principle while designing preventive interventions. The aim of this study was to investigate the prevalence rate and determinants of SU in adolescents based on the social development model (SDM).

Method In 2018, applying a cross-sectional design, cluster multistage random sampling was employed to recruit 600 adolescents in Bam County, Iran, to participate in the study. A valid and reliable SDM-based instrument was used to collect data.

Results The prevalence rate of using at least one substance was $42 \%$ (in girls $33.6 \%$ and in boys $50.3 \%$ ). Having close friends with SU was found as the riskiest factor. A score increase in involvement in prosocial activities and interactions, attachment and commitment to prosocial others (family and school), and skills for interaction/involvement among adolescents reduced the probability of ever use of SU by $53 \%, 37 \%$ and $49 \%$, respectively. Also, one score increase in perceived rewards for antisocial interaction/involvement, belief in antisocial values and situational perception among the participants increased the probability of ever use SU by $2.22,2.24$ and 1.22 times.

Conclusion The SDM was helpful in determining the predictors of SU among Iranian adolescents. In community-based interventions to prevent SU among adolescents, a great focus should be firstly on identifying the probability of SU in close friends. Moreover, the involvement of adolescents in prosocial activities and interactions, attachment and commitment to prosocial others (family and school), and skills for interaction/involvement should be core categories while designing community-based interventional studies.

\section{Background}

Nowadays, substance use (SU) including alcohol, tobacco and other drugs (ATOD) in adolescents is known as one of the most important health and social problems throughout the world. Due to teenage period characteristics (including the creation of a position to challenge feelings, showing a sense of independence, acceptance by the peer-group and reducing stress), adolescents may fancy abuse a wide range of substances like opium, cannabis, tobacco and alcohol [1-2]. SU in adolescence leads to severe consequences such as unintentional injuries, cancer, suicide and murder, depression, personality disorders, unplanned sex and sexually transmitted infections (STDs) [3]. SU may also lead to social damages, such as education failure, school expulsion, unemployment, delinquency, poverty, etc [3-4]. Therefore, SU considered as one of the most important obstacles to countries' social development $[1,5]$.

In the south east of Iran access to drugs is relatively easy, which is due to the proximity and having the longest common geographical boundary with two drugs manufacturing countries (Afghanistan and Pakistan). In Iran, SU is considered as the fourth risk factor for mortality, after road accidents, cardiovascular diseases and burns. It also imposes three billion dollars cost and damage to Iran's economy, annually [6-7]. Previous studies have shown a relatively high prevalence of SU in Iranian adolescents. 
According to Jalilian et al., current use and ever use of waterpipe (WP) smoking were 7.9\% and 21.6\%, respectively [6]. In Tehran, the current use of WP was 17.6\%[8]. In another study, the prevalence of tobacco use, alcohol consumption and narcotics use were reported to be $28.3 \%, 13 \%$, and $5.2 \%$, respectively [9]. In a meta-analysis on Iranian studies, the prevalence of WP, cigarette and alcohol use among high school students were $23.1 \%, 16.8 \%$ and $14.7 \%$, respectively [10].

One of the most important strategies to control and reduce SU in adulthood is to prevent the issue among adolescents [11]. Because more than $90 \%$ of adults with SU disorders, have experienced the behavior before the age of 18 and about half of them have experienced it prior to the age of 15 [12]. Considering the teenage period as a sensitive and high-risk period on bringing people to SU and addiction, the recognition of SU patterns and its related factors is detrimental in developing effective SU prevention programs among adolescents $[5,11,13]$. Also, considering the decrease in the first age of SU, surveys are suggested to monitor the age of SU in order to adopt effective interventions [14].

\section{1-1 Theoretical framework}

Theoretical frameworks have shown promise in finding better understandings on the reasons underpinning human behaviors and the associated factors among different populations. One of the behavioral models designed to predict and plan for delinquency behaviors prevention programs is the Social Development Model (SDM) [15]. According to the SDM, adolescents learn social and antisocial behaviors from family, school, social institutions and their peers during the process of socialization [16]. The social development model helps explain the behavior by measuring these constructs: Perceived opportunity for pro/antisocial interaction/involvement, Involvement in pro/antisocial activities and interactions, perceived rewards for pro/antisocial interaction/involvement, attachment and commitment (bonding) to pro/antisocial others and activities, belief in moral others or antisocial values and skills for interaction/involvement [15-16]. As SU is a public health concern that origins from the social context of societies, we chose to consider SDM as the theoretical framework for our study. We assume that the SDM is helpful in explaining the protective and risk factors of SU among adolescents.

\section{1-2 Objectives}

The following questions guided our study: 1) what is the prevalence of SU among adolescents in Iran, as a developing country? 2) To what extent may the constructs of SDM be associated with SU among the adolescents? and 3) May the SDM be applied as a framework for designing SU prevention programs in a developing country like Iran? Therefore, in the present study we aimed to examine the prevalence and determinants of SU among adolescents in Bam County, Iran.

\section{Methods}

2.1 participants and sampling 
In this cross-sectional study, 600 high school students, 300 girls and 300 boys in Bam County, Kerman province, the southeast of Iran, were recruited to participate in the study from April to June 2018. Bam, with a population about 230000 inhabitants, is located in the southeastern part of Iran, and in the transit path of drugs to the western borders of Iran and Europe. Applying a multistage random sampling method, Bam County was stratified into 6 regions. From each region, a high school (a female and a male high school) was selected. Next, from all the 10th (141 boys and 101 girls), 11th (145 boys and 99 girls), and 12th (14 boys and 100 girls) grades in the selected schools, the participants were selected through proportional sampling. Inclusion criteria were written agreement from the school authorities and one of the parents of students, and students' willingness to participate in the study. The purpose of study was explained to the participants, and all then completed the self-report questionnaires. Data were collected using the sealed ballot box method. Also, to increase confidentiality and the accuracy of responses, the respondents were asked to answer the questionnaires outside the classroom and in a more open space (such as school hall) without the presence of school administrators.

\subsection{Questionnaire}

The instrument was an SDM-based 65-item valid and reliable questionnaire developed by Iranpour et al [17]. The questionnaire consisted 2 sections:

The first section included 55 items based on the constructs of SDM: Involvement in anti/prosocial activities and interactions (8 items), perceived opportunity for anti/prosocial interaction/involvement (8 items), attachment and commitment (bonding) to pro/antisocial others (5 items), perceived rewards for prosocial interaction/involvement (3 items), perceived rewards for antisocial interaction/involvement (SU) (11 items), belief in others' morals or antisocial values (10 items), and skills for interaction/involvement ( 6 items) and SU by intimate friends (4 items). A 5-point Likert-type scaling ( $1=$ strongly agree to $5=$ strongly disagree or $1=$ very much to $5=$ none) was used as response format for all scales except for "SU by intimate friends" which was scored based on a dichotomous format (yes/no). The scores in each scale were then summed to find out the total score. Internal consistency of the questionnaire was determined by Cronbach's alpha coefficient among 30 students. The coefficients for all constructs were above 0.71 (range: 0.71-0.90).

The second section (SU behavior scale), included 10 items with a "Yes/No" response format that asked the participants on their experience (Ever Use) on the use of substances in the last 30 days (Current Use). The items included 10 questions on 5 most commonly used substances (hookah, cigarettes, alcohol, opium and hashish) among Iranian high school students, as reported in a previous study[18].

\subsection{Statistical analysis}

Descriptive analytical tests such as mean and standard deviation were used to describe the results and to assess relationships between the constructs of SDM and SU by gender. Applying IBM SPSS v.22 software, multiple linear regressions were also performed to investigate the predicting factors of SU. The 
relationships between the SDM constructs and SU behaviors were also analyzed using path analysis in the AMOS v.18 software. The significance level of all tests in this study was considered 0.05 , a priori.

\subsection{Ethical considerations}

The proposal of study was approved by the Ethics Committee in Kerman University of Medical Sciences (IR.KMU.AH.REC.1395.90). All ethical considerations were presented to the participants and one of their parents and all signed written consent forms. In order to increase the confidence of students and to ensure that they remain unknown, demographic characteristics other than age, gender and grade were also eliminated. Also, the questionnaires were anonymous and the items were designed as non-sensitive as possible.

\section{Results}

The mean age of participants was $16.78 \pm 0.74$. The prevalence rates of ever use for at least one substance were $50.3 \%$ and $33.7 \%$ for boys and girls, respectively, and the rate of current use for at least one substance were $34 \%$ and $9.3 \%$ for boys and girls, respectively (Table 1 ).

Table 1

The prevalence rates for ever and current use of different SU in participants

\begin{tabular}{|lllllll|}
\hline SU* & \multicolumn{5}{l}{ Ever use } & \multicolumn{5}{l|}{ Current use } \\
\cline { 2 - 7 } & Girls & Boys & Total & Girls & Boys & Total \\
\cline { 2 - 6 } & $\mathbf{N}(\%)$ & & & & & \\
\hline Hookah & $93(31)$ & $136(45.3)$ & $229(38.2)$ & $24(8)$ & $80(26.7)$ & $104(17.3)$ \\
\hline Alcohol & $19(6.3)$ & $101(33.7)$ & $120(20)$ & $2(0.07)$ & $74(24.7)$ & $76(12.7)$ \\
\hline Smoking & $17(5.7)$ & $43(14.3)$ & $60(10)$ & $5(1.7)$ & $22(7.3)$ & $27(4.5)$ \\
\hline Opium & $3(1)$ & $10(3.3)$ & $13(2.2)$ & $1(0.3)$ & $8(2.7)$ & $9(1.5)$ \\
\hline Cannabis & $0(0)$ & $13(3.4)$ & $13(2.2)$ & $0(0)$ & $11(3.7)$ & $11(1.8)$ \\
\hline $\begin{array}{l}\text { At least one of the } \\
\text { substances }\end{array}$ & $101(33.7)$ & $151(3.50)$ & $252(42)$ & $28(3.9)$ & $102(34)$ & $130(21.7)$ \\
\hline *SU: substance & & & & & & \\
\hline
\end{tabular}

Among peers (intimate friends), the most abusive substance was tobacco (hookah/cigarette) with $35.7 \%$ in boys and $18.3 \%$ in girls, and the least abusive one was opium (3.3\%), as reported by participants. In general, about $32.8 \%$ of the peers of participants have experienced at least one of the four studied substances. Also, among those who experienced at least one substance, $59.9 \%$ of their close friends were also drug users (Table 2). 
Table 2. The frequency of SU in close friends of the participants

\begin{tabular}{|llll}
\hline SU* & \multicolumn{3}{l}{ Experience of substance in close friends } \\
\cline { 2 - 4 } & Girls & Boys & Total \\
\cline { 2 - 4 } & $\mathrm{N}(\%)$ & & \\
\hline Hookah/Smoking & $55(18.3)$ & $107(35.7)$ & $162(27)$ \\
\hline Alcohol & $15(5)$ & $121(40.3)$ & $136(22.7)$ \\
\hline Opium & $5(1.7)$ & $15(5)$ & $20(3.3)$ \\
\hline Cannabis & $2(0.7)$ & $20(6.7)$ & $22(3.7)$ \\
\hline At least one of the substances & $57(19)$ & $140(46.7)$ & $197(32.8)$ \\
\hline *SU: substance Use & & & \\
\hline
\end{tabular}

\subsection{Independent variable: ever use}

Risk and protective factors: The SU in close friends was found as a very strong risk factor for SU among the adolescents in a way that, adjusted for confounding factors, the probability of SU in participants whose close friends abused at least one of the substances was 5.88 more than those among the participants without such close friends (Table 3).

As there is shown in Table 3, a score increase in involvement in prosocial activities and interactions, attachment and commitment to prosocial others (family and school), and skills for interaction/involvement among adolescents reduced the probability of ever use of SU by $53 \%, 37 \%$ and $49 \%$, respectively. Also, one score increase in perceived rewards for antisocial interaction/involvement, belief in antisocial values and situational perception among the participants increased the probability of ever use of SU by 2.22, 2.24 and 1.22 times (Table 3). 
Table 3. Determinants of at least one substance use among adolescents based on the Social Development Model constructs and demographic variables

\begin{tabular}{|c|c|c|c|c|c|c|c|}
\hline \multirow{2}{*}{\multicolumn{2}{|c|}{ Variables }} & \multicolumn{3}{|c|}{ Univariate regression } & \multicolumn{3}{|c|}{ Multivariate regression } \\
\hline & & $\mathrm{OR}$ & $95 \% \mathrm{Cl}$ & p-value & OR & $95 \% \mathrm{Cl}$ & p-value \\
\hline \multicolumn{2}{|c|}{$\begin{array}{l}\text { Involvement in pro social activities and } \\
\text { interactions }\end{array}$} & 0.33 & $\begin{array}{l}(0.24 \\
-0.44)\end{array}$ & $P<0.001$ & 0.47 & $\begin{array}{l}(0.33 \\
- \\
0.66)\end{array}$ & $P<0.001$ \\
\hline \multicolumn{2}{|c|}{$\begin{array}{l}\text { Perceived opportunity for prosocial } \\
\text { interaction/involvement }\end{array}$} & 0.54 & $\begin{array}{l}(0.40- \\
0.72)\end{array}$ & $P<0.001$ & 0.76 & $\begin{array}{l}(0.55 \\
\frac{1}{1.06)}\end{array}$ & $P=0.113$ \\
\hline \multicolumn{2}{|c|}{$\begin{array}{l}\text { Attachment and commitment to } \\
\text { pro/antisocial others (family and } \\
\text { school) }\end{array}$} & 0.59 & $\begin{array}{l}(0.47- \\
0.73)\end{array}$ & $P<0.001$ & 0.73 & $\begin{array}{l}(0.93 \\
\overline{0} \\
0.58)\end{array}$ & $P=0.011$ \\
\hline \multicolumn{2}{|c|}{$\begin{array}{l}\text { Perceived rewards for prosocial } \\
\text { interaction/involvement }\end{array}$} & 0.80 & $\begin{array}{l}(0.67- \\
0.95)\end{array}$ & $P=0.014$ & 0.88 & $\begin{array}{l}(0.72 \\
1.08)\end{array}$ & $P=0.240$ \\
\hline \multicolumn{2}{|c|}{$\begin{array}{l}\text { Perceived rewards for antisocial } \\
\text { interaction/involvement }\end{array}$} & 4.00 & $\begin{array}{l}(5.88- \\
2.78)\end{array}$ & $P<0.001$ & 2.22 & $\begin{array}{l}(3.22 \\
- \\
1.53)\end{array}$ & $P<0.001$ \\
\hline \multicolumn{2}{|c|}{$\begin{array}{l}\text { Belief in moral others or antisocial } \\
\text { values }\end{array}$} & 1.72 & $\begin{array}{l}(1.43- \\
2.07)\end{array}$ & $P<0.001$ & 1.22 & $\begin{array}{l}(0.98 \\
1.51)\end{array}$ & $P=0.065$ \\
\hline \multicolumn{2}{|c|}{ belief in antisocial values } & 3.03 & $\begin{array}{l}(4- \\
2.38)\end{array}$ & $P<0.001$ & $2.24^{\star \star \star}$ & $\begin{array}{l}\frac{(2.94}{1.67)} \\
-\end{array}$ & $P<0.001$ \\
\hline \multicolumn{2}{|c|}{ skills for interaction/involvement } & 0.40 & $\begin{array}{l}(0.32- \\
0.50)\end{array}$ & $P<0.001$ & 0.51 & $\begin{array}{l}(0.39 \\
\overline{0} \\
0.67)\end{array}$ & $P<0.001$ \\
\hline \multicolumn{2}{|l|}{ Grade } & 0.84 & $\begin{array}{l}(0.67- \\
1.05)\end{array}$ & $P=0.139$ & 1.04 & $\begin{array}{l}(0.79 \\
1.38)\end{array}$ & $P=0.730$ \\
\hline \multirow[t]{2}{*}{ Gender } & Girls & 1 & - & - & 1 & - & - \\
\hline & Boys & 1.99 & $\begin{array}{l}(1.43- \\
2.77)\end{array}$ & $P<0.001$ & 0.72 & $\begin{array}{l}(0.45 \\
1.16)\end{array}$ & $P=0.182$ \\
\hline \multirow[t]{2}{*}{ SU in close friends } & No & 1 & - & - & 1 & - & - \\
\hline & Yes & 9.81 & $\begin{array}{l}(6.58- \\
14.63)\end{array}$ & $P<0.001$ & 5.88 & $\begin{array}{l}(3.72 \\
\frac{9}{9.29)}\end{array}$ & $P<0.001$ \\
\hline
\end{tabular}


Using the path analysis to identify the relationships between the SDM constructs and the SU behavior among participants, we found almost all SDM constructs with statistically significant direct effects $(p<0.0001)$ on the SU behavior, except for positive rewards (Table 4 and Figure 1$)$. The indirect effect of gender on the SU behavior was close to zero, showing no effect on the SU.

Table 4. Analysis of the relationship between the SDM constructs and ever use of ATOD in participants

\begin{tabular}{|c|c|c|c|c|c|c|}
\hline \multirow[t]{2}{*}{ variable } & \multirow{2}{*}{$\begin{array}{l}\text { Coefficient of } \\
\text { regression } \pm S D\end{array}$} & \multirow[t]{2}{*}{ Z } & \multirow[t]{2}{*}{ P-value } & \multicolumn{3}{|c|}{ Standardized effect } \\
\hline & & & & $\begin{array}{l}\text { Direct } \\
\text { effects }\end{array}$ & $\begin{array}{l}\text { Indirect } \\
\text { effects }\end{array}$ & $\begin{array}{l}\text { Total } \\
\text { effects }\end{array}$ \\
\hline $\begin{array}{l}\text { Perceived Opportunity } \\
\rightarrow \text { Involvement }\end{array}$ & $0.42 \pm 0.04$ & +10.78 & $0<0.0001$ & +0.40 & 0 & +0.40 \\
\hline $\begin{array}{l}\text { Involvement } \rightarrow \text { Positive } \\
\text { reward }\end{array}$ & $0.44 \pm 0.06$ & +1.39 & $0<0.0001$ & +0.29 & +0.02 & +0.31 \\
\hline $\begin{array}{l}\text { Positive reward } \rightarrow \\
\text { Bonding }\end{array}$ & $0.39 \pm 0.03$ & +17.96 & $0<0.0001$ & +0.58 & 0 & +0.58 \\
\hline $\begin{array}{l}\text { Bonding } \rightarrow \text { Situational } \\
\text { perception }\end{array}$ & $0.29 \pm 0.05$ & -7.13 & $0<0.0001$ & -0.28 & 0 & -0.28 \\
\hline Gender $\rightarrow$ Opportunities & $-0.06 \pm 0.05$ & -1.16 & 0.24 & -0.04 & 0 & -0.04 \\
\hline $\begin{array}{l}\text { Involvement } \rightarrow \\
\text { Negative reward }\end{array}$ & $-0.33 \pm 0.05$ & -6.95 & $0<0.0001$ & 0.27 & 0 & 0.27 \\
\hline Skill $\rightarrow$ Positive reward & $0.09 \pm 0.05$ & 1.89 & 0.06 & 0.08 & 0 & 0.08 \\
\hline $\begin{array}{l}\text { Positive reward } \rightarrow \\
\text { Behavior }\end{array}$ & $0.016 \pm 0.02$ & -1.00 & 0.48 & -0.032 & +0.018 & -0.014 \\
\hline $\begin{array}{l}\text { Situational perception } \\
\rightarrow \text { Behavior }\end{array}$ & $0.049 \pm 0.01$ & +4.4 & $0<0.0001$ & 0.197 & 0 & 0.197 \\
\hline $\begin{array}{l}\text { Negative reward } \rightarrow \\
\text { Behavior }\end{array}$ & $+0.12 \pm 0.02$ & +4.75 & $0<0.0001$ & +0.18 & 0 & +0.18 \\
\hline $\begin{array}{l}\text { Belief in moral } \rightarrow \\
\text { Behavior }\end{array}$ & $-0.16 \pm 0.02$ & -6.7 & $0<0.0001$ & -0.27 & 0 & -0.27 \\
\hline Involvement $\rightarrow$ Skills & $+0.37 \pm 0.05$ & +7.12 & $0<0.0001$ & +0.28 & 0 & +0.28 \\
\hline
\end{tabular}

\section{Discussion}

The aim of this study was to investigate the prevalence rate of SU and its risk and protective factors among Iranian adolescents in Bam County, Iran. Considering adolescence as the riskiest period of life to start SU, it seems necessary to investigate the determinants of adolescents' tendency towards SU $[16,19]$, with the hope to identify the most effective and relevant stratgies for interventional efforts. In the present study, using hookah, alcohol and cigarette were the most commonly reported substances by the participants. These results are consistent with those reported or higher than in several previous studies 
throughout the world [5, 20-25]. Also, more than $38 \%$ of the participants experienced hookah $(45.3 \%$ in boys and $31 \%$ in girls), $20 \%$ consumed alcohol (33.7\% in boys and $6.3 \%$ in girls), and $10 \%$ smoked cigarette ( $14.3 \%$ in boys and $5.7 \%$ in girls). These results are in line with those of similar studies among adolescents in Kerman province (the setting of our study), and higher than those of previous studies among Iranian adolescents outside the Kerman Province [26]. Comparing our results with those of similar previous studies in this setting $[24,27]$.

In our study, there was a remarkable difference between the prevalence rates of hookah $(38.1 \%)$ and cigarette (10\%) smoking. Previous studies have shown that adolescents consider hookah smoking as a less risky and less addictive behavior, compared to other modes of tobacco use. Also, in our setting, hookah is much more readily available to adolescents than other forms of tobacco products at restaurants, traditional cafe shops and even the adolescents' homes. Moreover, there is a lower level of social stigma against hookah use, compared to the other forms of substances. So, it is so easy for the teenagers to do the behavior $[26,28]$.

Assessing the relationships between the SDM constructs and SU behavior, we found that involvement in pro/anti-social activities and interactions, attachment and commitment (bonding) to prosocial others and activities (family and school), perceived rewards for pro/antisocial interaction/involvement, as well as belief in others' morals or antisocial values, and skills for interaction/involvement were the most significant predictors of SU. These results are consistent the assumptions of SDM and those reported in previous studies on the risk and protective factors of SU $[15,19]$.

In the present study, we found that participation in prosocial activities and belief in prosocial values derived from social environments such as family, school and peer groups had a protective role against SU, suggesting them as detrimental factors to be considered while designing SU prevention interventions. SU by one's close friends was found to be a very strong risk factor for tendency towards SU among the participants, which is consistent with those reported in previous similar studies [6, 29-30]. These findings necessitate particular considerations on the strategies applied while designing interventional efforts. We should pay attention that adolescence is a period of age when the impact of parents on the child decreases, gradually, and the impact of peer groups is increased instead. In adolescence, also, having abusive peers can be a risk factor, but if the peers have prosocial behaviors, it can be considered as a protective factor[5, 31-32]. Therefore, strengthening bonding with family, school and prosocial communities may lead to receiving more positive social support and decreasing stress among adolescence [31].

In several previous studies, having a positive attitude towards hookah, cigarette and alcohol, lack of skills to cope with the other's recommendations, having friends (peers) who use substances, weakness of parent-child relationships, lack of bonding with school, and incorrect cultural beliefs and mores, weakness of religious beliefs in society are mentioned as the most common reasons for teenager tendency towards SU, which is consistent with those found in our study [11, 30,33]. Despite Iran's intense struggle with drug trafficking during the last 40 years, and due to the easy access to ATOD in the studied 
area, an increase in the prevalence rate of SU in Iranian population is undeniable. So, the country requires a careful observation on the prevalence of SU and an overview of the coping methods. We need to pursue indirect coping ways based on scientific frameworks such as SDM. Based on our findings, bonding with family and school and joining prosocial peer groups were the most important protective factors against $\mathrm{SU}$, as an antisocial behavior. Therefore, interventional efforts should be focused on families and schools (particularly preschool and elementary schools) from the ages younger than adolescence. Therefore, life skills training for teachers and parents of children under 12 years of age may be helpful in making better bonding of children to their school and family members, when they will become a teenager in their society.

\section{Limitations}

In this study, in order to achieve more credible results and increase the confidence of students, we did not ask many important variables such as the level of parents' literacy and the socioeconomic status of the family. Moreover, the present study was cross-sectional in nature and the results of longitudinal studies may be more helpful in studying the risk and protective factors of SU. As another limitation of the study, the research was conducted in urban area, only. Future studies should be carried out in rural communities to find a better understanding on SU in both urban and rural areas.

\section{Conclusion}

The SDM was helpful in determining the predictors of SU among Iranian adolescents. In communitybased interventions to prevent SU among adolescents, a great focus should be firstly on identifying the probability of SU in close friends. Moreover, the involvement of adolescents in prosocial activities and interactions, attachment and commitment to prosocial others (family and school), and skills for interaction/involvement should be core categories while designing interventional efforts. In the life skills training courses for school staff and parents, empowering parents and teachers on how to reward adolescents for their antisocial interaction/involvement, and how to promote antisocial values and situational perceptions among adolescents are recommended.

\section{Declarations}

\section{Ethics approval and consent to participate}

Ethical approval was obtained from the institutional review board of the Kerman University of medical Sciences. (Ethics approval code: IR.KMU.AH.REC.1395.90). Written informed consent was obtained from all students and at least one of their parents prior to their participation.

\section{Consent for publication}

Not applicable. 


\section{Availability of data and materials}

The datasets used and/or analyzed during the current study are available from the corresponding author on reasonable request.

\section{Competing Interests}

The authors declare that they have no conflict of interest.

\section{Funding}

Kerman University of Medical Sciences, Kerman, Iran

\section{Authors' contributions}

Study design by Al and NN. Conceptualization by Al. Drafting of the manuscript by Al, HN and RSh.

Analysing data by YJ and HN. Data collection by RSh. Methodology by Al and HSh. Critical revision of the manuscript for important intellectual content and Project administration and Validation by $\mathrm{Al}, \mathrm{HN}$ and $\mathrm{HK}$. Supervision by Al and MMF. Writing, reviewing, and editing by HK and HN.

\section{Acknowledgements}

The authors extend their appreciation to the participants for their cooperation throughout the study. They also appreciate the assistance of the members of the Ethics and Research Boards of Kerman University of Medical Sciences.

\section{Conflict of Interest}

The authors declare that they have no conflict of interest.

\section{Informed consent}

Informed consent was obtained from all individual participants included in the study.

\section{References}

1. Jetty, R., Tobacco use and misuse among Indigenous children and youth in Canada. Paediatrics \& child health, 2017. 22(7): p. 395-399. 
2. Mahboubi, S., et al., Sibling cigarette smoking and peer network influences on substance use potential among adolescent: a population based study. International journal of adolescent medicine and health, 2017.

3. Odgers, C.L., et al., Is it important to prevent early exposure to drugs and alcohol among adolescents? Psychological Science, 2008. 19(10): p. 1037-1044.

4. McCann, U.D. and G.A. Ricaurte, Drug abuse and dependence: hazards and consequences of heroin, cocaine and amphetamines. Current Opinion in Psychiatry, 2000. 13(3): p. 321-325.

5. Karimy, M., et al., Refusal self efficacy, self esteem, smoking refusal skills and water pipe (Hookah) smoking among iranian male adolescents. Asian Pacific Journal of Cancer Prevention, 2013. 14(12): p. 7283-7288.

6. Jalilian, F., et al., Socio-demographic characteristics associated with cigarettes smoking, drug abuse and alcohol drinking among male medical university students in Iran. Journal of research in health sciences, 2015. 15(1): p. 42-46.

7. Pirdehghan, A., M.P. Rezaee, and B. Mirzababaee, Epidemiology of Substance Abuse Among Iranian Adolescents (Yazd: 2014). Iranian Journal of Psychiatry and Behavioral Sciences, 2017. 11(4).

8. Hessami, Z., et al., Evaluation of the prevalence of waterpipe tobacco smoking and its related factors in Tehran, Islamic Republic of Iran. EMHJ-Eastern Mediterranean Health Journal, 2017. 23(2): p. 9499.

9. Heydarabadi, A.B., et al., Prevalence of substance abuse among dormitory students of Shahid Beheshti University of Medical Sciences, Tehran, Iran. International journal of high risk behaviors \& addiction, 2015. 4(2).

10. Ansari-Moghaddam, A., et al., Prevalence and patterns of tobacco, alcohol, and drug use among Iranian adolescents: A meta-analysis of 58 studies. Children and Youth Services Review, 2016. 60: p. 68-79.

11. Rezaei, F., et al., The role of social and familial factors as predicting factors related to hookah and cigarette smoking among adolescents in Jahrom, South of Iran. International Journal of Pediatrics, 2017. 5(5): p. 4929-4937.

12. Kelishadi, R., et al., Determinants of tobacco and hookah smoking in a nationally representative sample of Iranian children and adolescents: The Caspian-IV Study. Iranian Red Crescent Medical Journal, 2016. 18(8).

13. Cleveland, M.J., et al., The role of risk and protective factors in substance use across adolescence. Journal of Adolescent Health, 2008. 43(2): p. 157-164.

14. Gallimberti, L., et al., Prevalence of substance use and abuse in late childhood and early adolescence: What are the implications? Preventive medicine reports, 2015. 2: p. 862-867.

15. Hawkins, J.D., R.F. Catalano, and M.W. Arthur, Promoting science-based prevention in communities. Addictive behaviors, 2002. 27(6): p. 951-976.

16. Catalano, R.F., et al., Modeling the etiology of adolescent substance use: $A$ test of the social development model. Journal of drug issues, 1996. 26(2): p. 429-455. 
17. Iranpour, A., et al., Development and psychometric properties of risk and protective factors of substance use scale in Iran: an application of social development model. Addiction \& health, 2015. 7(3-4): p. 117.

18. Nahvizadeh, M.M., et al., A review study of substance abuse status in high school students, Isfahan, Iran. International Journal of Preventive Medicine, 2014. 5(Suppl 2): p. S77.

19. Arthur, M.W., et al., Implementation of the Communities That Care prevention system by coalitions in the Community Youth Development Study. Journal of Community Psychology, 2010. 38(2): p. 245258.

20. Galimov, A., et al., Hookah Use among Russian adolescents: Prevalence and correlates. Addictive behaviors, 2019. 90: p. 258-264.

21. Ghizzone, M. and H.J. Farber, Social hookah smoking prevalent among adolescents. Infectious Diseases in Children, 2018. 31(8): p. 18-18.

22. Majeed, B.A., et al., Prevalence and harm perceptions of hookah smoking among US adults, 20142015. Addictive behaviors, 2017. 69: p. 78-86.

23. Manderski, B., et al., Hookah use among New Jersey youth: associations and changes over time. American journal of health behavior, 2012. 36(5): p. 693-699.

24. Nakhaee, N., H. Ziaaddini, and A. Karimzadeh, Epidemiologic study on drug abuse among first and second grade high school students in Kerman. Addiction \& health, 2009. 1(1): p. 31.

25. Poorasl, A.M., et al., Substance abuse in Iranian high school students. Addictive behaviors, 2007. 32(3): p. 622-627.

26. Fakhari, A., et al., Hookah smoking in high school students and its determinants in Iran: a longitudinal study. American journal of men's health, 2015. 9(3): p. 186-192.

27. Ziaaddini, H., et al., The prevalence of at least one-time substance abuse among Kerman preuniversity male students. Addiction \& health, 2010. 2(3-4): p. 103.

28. Rajabalipour, M., et al., Application of social cognitive theory to prevent waterpipe use in male highschool students in Kerman, Iran. International Journal of Preventive Medicine, 2019. 10(1): p. 186.

29. Deng, S. and M.W. Roosa, Family influences on adolescent delinquent behaviors: Applying the social development model to a Chinese sample. American Journal of Community Psychology, 2007. 40(34): p. 333-344.

30. Wongtongkam, N., et al., The influence of protective and risk factors in individual, peer and school domains on Thai adolescents' alcohol and illicit drug use: A survey. Addictive Behaviors, 2014. 39(10): p. 1447-1451.

31. Bahmanpour, K., et al., Determinants of oral health behavior among high school students in Marivan County, Iran based on the Pender's Health Promotion Model. Journal of School of Public Health \& Institute of Public Health Research, 2011. 9(2).

32. Botvin, G.J. and K.W. Griffin, Drug abuse prevention curricula in schools, in Handbook of drug abuse prevention. 2006, Springer. p. 45-74. 
33. Abbasi-Ghahramanloo, A., et al., Prescription drugs, alcohol, and illicit substance use and their correlations among medical sciences students in Iran. International journal of high risk behaviors \& addiction, 2015. 4(1). 